\title{
Regulation of Apoptosis by Nitrosative Stress
}

\author{
Ki-Mo Kim†, Peter K.M. Kim, Young-Guen Kwon', Se-Kyung Bai ${ }^{\S}$, \\ Woo-Dong Nam" and Young-Myeong Kim, ${ }^{\dagger, * *}$ \\ †Vascular System Research Center, Kangwon National University, Chunchon, Kangwon-do, Korea \\ Department of Surgery, School of Medicine, University of Pittsburgh, Pittsburgh, PA15213 \\ ${ }^{\S}$ Department of Food and Nutrition, Division of Natural Sciences, Hallym University, Chunchon, Kangwon-do, Korea \\ Department of "Orthopaethic Surgery and "Molecular and Cellular Biochemistry School of Medicine, Chunchon, Kangwon-do, Korea
}

\section{Received 7 December 2001}

\begin{abstract}
Nitrosative stress can prevent or induce apoptosis. It occurs via S-nitrosylation by the interaction of nitric oxide (NO) with the biological thiols of proteins. Cellular redox potential and non-heme iron content determine Snitrosylation. Apoptotic cell death is inhibited by $S$ nitrosylation of the redox-sensitive thiol in the catalytic site of caspase family proteases, which play an essential role in the apoptotic signal cascade. Nitrosative stress can also promote apoptosis by the activation of mitochondrial apoptotic pathways, such as the release of cytochrome c, an apoptosis-inducing factor, and endonuclease $G$ from mitochondria, as well as the suppression of NF-kB activity. In this article we reviewed the mechanisms whereby $\mathrm{S}$ nitrosylation and nitrosative stress regulate the apoptotic signal cascade.
\end{abstract}

Keywords: Nitric oxide, Apoptosis, Nitrosative stress, Snitrosylation, Mitochondria

\section{NO synthesis and its action mode}

Nitric oxide (NO) is a short-lived, diffusible free radical that is produced from L-arginine in a reaction. It is catalyzed by one of the three isotypes of NO synthases (NOS)-endothelial NOS (eNOS), neuronal NOS (nNOS), or inducible NOS (iNOS) (Ignarro et al., 1987; Nathan, 1992). The functional role of NO can vary by cell type and enzyme isotype. The major function of eNOS is to regulate vascular tone. The main role for nNOS includes retrograde signaling across synapses. The primary inducible NOS isoform (iNOS) can be upregulated considerably via the activation of immune cells and many other tissues by the bacterial cell wall component

*To whom correspondence should be addressed.

Tel: 82-33-250-8831; Fax: 82-33-244-3286

E-mail: ymkim@kangwon.ac.kr lipopolysaccharide (LPS) and/or cytokines. At normal intracellular calcium levels, NO production by iNOS is limited only by the amount of enzyme, substrate, or co-factors that are present (Xie and Nathan, 1994; Gross and Wolin, 1995). In contrast, eNOS and nNOS are constitutively expressed and inactive at normal calcium concentrations, producing picomolar amounts of NO in response to transient increases in the cytosolic calcium level. However, chronic calcium elevation will cause persistent NO production (Ignarro et al., 1987; Nathan, 1992). NO interacts directly with several cellular target molecules before diffusing out of NO-producing cells. Since NO is relatively small and hydrophobic, it can easily pass through membranes. Because NO persists in vivo for a few seconds, it can diffuse several cell diameters from its site of synthesis (Lancaster, 1994). When co-cultured with red blood cells that scavenge biological NO, the formation of intracellular NO reaction products in the form of dinitrosyl iron complexes was dramatically suppressed in NO-producing hepatocytes (Nussler et al., 1993). This indicates that the transcellular diffusion of NO is more rapid than the rate of intracellular reaction with its target molecules within NO-generating cells. Consequently, the steady-state NO concentration that is experienced by a cell is determined by the number of NOproducing cells nearby (Beckman and Koppenol, 1996). NO that is produced within cells, therefore, interacts with biomolecules through both autocrine and paracrine modalities.

\section{Biochemical reactivity of NO}

$\mathrm{NO}$ decays to nitrite by a reaction with $\mathrm{O}_{2}$ in an aqueous buffer, and its decay rate is largely determined by the NO concentration (Kerwin and Feldman, 1995). At maximum biological concentrations $(1-5 \mu \mathrm{M})$, the half-life of NO in vitro is several minutes; it is far longer at more normal physiological concentrations (Ignarro et al., 1993; Kim et al., 1995). 
However, its biological half-life is less than $5 \mathrm{~s}$ (Ignarro et al., 1993). This suggests that in vivo, NO decays by a minimal reaction with oxygen, or through reaction pathways with other biological molecules (Kim et al., 1995). To put it simply, NO can react with molecular oxygen $\left(\mathrm{O}_{2}\right)$ to produce nitrite. However, this reaction is very slow at physiological concentrations of $\mathrm{O}_{2}$. NO reacts rapidly with $\mathrm{O}_{2}^{-}$to form the strong oxidant peroxynitrite $\left(\mathrm{ONOO}^{-}\right)$, a cytotoxic modulator (Beckman et al., 1990) and bactericidal agent (Zhu et al., 1991). NO also interacts with many heme-containing proteins. NO reacts with the heme-iron of hemoglobin and myoglobin to form nitrate. NO activates guanylate cyclase by binding to its heme-iron to generate cGMP from GTP, which plays a key role in vascular tone regulation and neurotransmission (Gruetter $e t$ al., 1980). The binding of NO to heme inhibits several heme enzymes, such as cytochrome oxidase, catalase, and cytochrome p450 (Kim et al., 1995). The reaction of NO with several biological components (such as metals, thiols, $\mathrm{O}_{2}$, and $\mathrm{O}_{2}^{-}$) produces a variety of secondary products that range from the innocuous oxidized components $\left(\mathrm{NO}_{2}^{-}\right.$and $\left.\mathrm{NO}_{3}^{-}\right)$to the reactive nitrogen intermediates, such as the nitrosonium equivalent $\left(\mathrm{NO}^{+}\right)$, peroxynitrite $\left(\mathrm{ONOO}^{-}\right)$, nitrosothiols (RSNO), nitroxyl anion $\left(\mathrm{NO}^{-}\right)$, dinitrogen trioxide $\left(\mathrm{N}_{2} \mathrm{O}_{3}\right)$, and nitrogen dioxide $\left(\mathrm{NO}_{2}\right)$ (Beckman et al., 1996). These reactive nitrogen species, including $\mathrm{NO}$, interact with biomolecules to cause lipid oxidation, protein modification (e.g. cysteine and tyrosine residue), DNA damage by base modification, and regulation of enzyme activity.

In nitrosation reactions, $N$-nitrosamines and $S$-nitrosothiols are formed by the addition of a nitrosonium equivalent $\left(\mathrm{NO}^{+}\right)$ to amine and thiol moieties, respectively (Gruetter et al., 1980). The activation of rodent macrophages with IFN- $\gamma$ and/ or LPS results in NO production by the iNOS gene expression and nitrosation of target molecules that are present in the culture medium (Gruetter et al., 1980; Zhu et al., 1991). Several iNOS-dependent reaction pathways have potential relevance in the nitrosation chemistry of biological systems. Acidified nitrite $\left(\mathrm{HNO}_{2}\right)$ is a nitrosating agent, but it is easily formed only in low $\mathrm{pH}$ environments, such as that of the stomach (Zhu et al., 1991). Dinitrosyl iron complexes from macrophages and hepatocytes that are activated by cytokines and LPS (Kim et al., 1995; Kim et al., 2000) may provide a mechanism for nitrosation, in particular, trans-S-nitrosation (Kim et al., 2000). Chemically synthesized dinitrosyl iron complexes induce the S-nitrosylation of caspase and albumin in vitro (Boese et al., 1995; Kim et al., 2000). Dinitrogen trioxide $\left(\mathrm{N}_{2} \mathrm{O}_{3}\right)$ that is formed by the reaction of $\mathrm{NO}$ with molecular oxygen has a strong propensity to nitrosate, both amine and thiol moieties at physiological $\mathrm{pH}$ (Kharitonov et al., 1995).

\section{NO induces $\mathrm{S}$-nitrosylation through nitrosative stress}

As clearly demonstrated, NO or related molecules can covalently modify cysteine residues in proteins through three chemical reactions S-nitrosylation, oxidation (RS-SR), and ADP-ribosylation. (Brune and Lapetina 1989; Stamler, 1994). These post-translational modifications serve in the regulation of cellular responses (Stamler, 1994; Stamler et al., 2001). Particularly, the redox-based S-nitrosylation of proteins or nonprotein thiols occurs both in vitro and in vivo (Brune and Lapetina, 1989; Kim et al., 1995). S-nitrosylation regulates the gene expression and cellular homeostasis through an alteration in protein function (Stamler, 1994; Kim et al., 1995; Chung et al., 2001). The concept of nitrosative stress has emerged from an understanding that nitrosylation can also reach hazardous levels. Under such conditions, nitrosylation may directly inhibit critical protein functions (Stamler, 1994), decrease redox potential (Chung et al., 2001), and/or promote deleterious oxidative modifications (Marshall et al., 2001). At the cellular level, nitrosative stress has been linked to the inhibition of cell growth and apoptosis, and thus may be widely implicated in the pathogenesis of many human diseases. In particular, the caspase proteolytic enzymes, key mediators for apoptotic cell death, possess a redox-sensitive cysteine residue in the catalytic site. NO could modify this enzyme by S-nitrosylation in vitro and in vivo, indicating that biological and chemical NO generation regulates apoptotic cell death.

\section{Caspase is a critical mediator in the apoptotic signal cascade}

Apoptosis, known as programmed cell death, is essential for the normal development of a multicellular organism, as well as the maintenance of tissue homeostasis (Steller, 1995). It is an active, energy-dependent process of cell shrinkage, plasma membrane blebbing, chromatin condensation, and DNA fragmentation. Apoptosis is biologically initiated by tightly controlled intracellular signaling events through the ligation of specific death receptors of the tumor necrosis factor receptor (TNF-R) family, such as tumor necrosis factor-alpha (TNF- $\alpha$ ), CD95/Fas/Apo-1, and the receptors for tumor necrosis factorrelated apoptosis-inducing ligand (TRAIL). Ligand binding of the trimerized receptor recruits intracellular adaptor molecules like FADD/MORT1 and TRADD into the death inducing signaling complex (DISC). It then recruits and activates the protease zymogen called procaspase- 8 (Boldin et al., 1996). The activation of caspase- 8 is known to involve the sequential activation of other caspases (Thornberry and Lazebnik, 1998). Caspases are constitutively expressed as inactive proenzymes in cells, and become activated by proteolytic processing when cells receive an apoptosis-inducing signal (Craen et al., 1999). Proteolytic cleavage results in the removal of an $\mathrm{N}$-terminal prodomain and generation of small (p10) and large (p20) active subunits, which form an active tetramer $(\mathrm{p} 10 / \mathrm{p} 20)_{2}$. Caspases are a family of cysteine proteases (consisting of 14 isoforms) which are the mammalian counterpart of ced-3, a protease that is required for programmed cell death in the 
nematode Caenorhabditis elegans (Nicholson et al., 1995). Some members (including caspase-8, -9, and 10) contain a large prodomain and are initiators of the apoptotic signal cascade. Others, such as caspase- $3,-6$, and 7 , possess a small prodomain and participate in the execution phase of apoptosis.

\section{Mitochondria are central subcellular organelles in apoptotic signaling}

There are two apoptotic signaling pathways that are mediated by the death receptor ligation and other proapoptotic stimuli. The activation of the cell surface death receptor (such as TNF$\alpha$ receptor, Fas, and TRAIL receptor) recruits procaspase- 8 to the DISC; caspase- 8 then becomes autoactivated. The active caspase- 8 can both directly activate downstream caspases, such as caspase-3, and cleave the cytochrome c-effluxing cytosolic factor Bid into two fragments (Luo et al., 1998; Li et al., 1998). The C-terminal p15 fragment translocates into mitochondria, and induces the release of cytochrome $\mathrm{c}$ and endonuclease $\mathrm{G}$ into the cytosol (Li et al., 2001).

On the other hand, receptor-independent inducers of apoptosis (such as the growth factor withdrawal, ultraviolet irradiation, and chemotherapeutic drugs) will provoke the release of mitochondrial cytochrome $\mathrm{c}$ and endonuclease $\mathrm{G}$ release without the activation of caspase- 8 activation, probably through the induction of mitochondrial membrane damage. The redistribution of cytochrome $\mathrm{c}$ by treatment with apoptosis-inducing stimuli can be prevented by antiapoptotic oncogenes, such as Bcl-2 and Bcl- $\mathrm{X}_{\mathrm{L}}$ (Yang et al., 1997). Many studies have revealed that cytosolic cytochrome $\mathrm{c}$ interacts with Apaf-1 and procaspase-9 and forms the "apoptosome" in the presence of dATP, which results in the activation of caspase-9 (Liu et al., 1996). The active caspase-9 leads to the activation of the downstream protease caspase-3, which is thought to assure the cleavage of target proteins that are required to complete the terminal events in apoptosis. For example, the cleavage of the DNA fragmentation factor (DFF) in humans (Liu et al., 1997), or the murine analogue inhibitor of caspase-activated DNase (ICAD) (Enari et al., 1998) by caspase-3-like caspases, leads to the release of activated CAD. It then translocates into the nucleus, which results in DNA degradation and apoptotic cell death (Sakahira et al., 1998).

Recent studies, however, have shown that as result of mitochondrial membrane damage that is induced by tBid or other toxic reagents, endonuclease $\mathrm{G}$ is released into the cytosol. It then translocates into nuclei to induce interchromosomal DNA fragmentation (Li et al., 2001). This endonuclease is found mostly in the intermembrane space with only a small fraction participating in the mitochondrial DNA replication in the matrix. The release of the mitochondrial endonuclease $G$ represents a caspaseindependent apoptotic pathway of mammalian cell death that is initiated from mitochondria. It will be interesting to see where on the evolutionary tree the endonuclease $G$ (in different species) acquired this death-promoting character.
Perhaps the endonuclease $G$ is responsible for some of the caspase-independent cell deaths and DNA fragmentation that have been observed in plants, fungi, and protozoa.

\section{Nitrosative stress inhibits caspase activity by S-nitrosylation}

NO regulates either the induction of apoptosis in some cells, or the prevention of apoptosis in others (Kim et al., 1999). High levels of NO production are known to be cytotoxic through the suppression of ATP synthesis by the inhibition of mitochondrial aconitase and mitochondrial complexes I and II (Brown, 1999), induction of the p53 expression (Brockhaus and Brune, 1999), and the inhibition of the rate-limiting enzyme of DNA synthesis, ribonucleotide reductase (Kwon et $a l ., 1991)$. The iNOS induction in macrophage cells by IFN- $\gamma /$ LPS induces nitrosative stress by increasing the formation of $\mathrm{S}$-nitrosylated proteins, which is a critical factor for the NOmediated apoptotic cell death (Fisch et al., 2000). However, we, as well as others, have shown in vitro and in vivo that $\mathrm{NO}$ protects several cells (including hepatocytes, neuronal PC12 cells, and endothelial cells) from cytotoxic stimuli, such as TNF- $\alpha$, Fas, serum deprivation, and oxidative stress (Kim et al., 1995; Kim et al., 1997; Kim et al., 1999; Kwon et al., 2001). Low level of endogenous NO production or NO from exogenous NO donors was previously shown to prevent apoptosis in human B lymphocytes (Mannick et al., 1994), ovarian follicles (Chun et al., 1995), neuronal cells (Kim et al., 1999), MCF-7 breast cancer cells (Kim et al., 1998), Jurkat T lymphocytes (Mannick et al., 1997), endothelial cells (Tzeng et al., 1997; Kwon et al., 2001), and hepatocytes (Kim et al., 1997; Kim et al., 1998). Several mechanisms for the antiapoptotic effect of NO have been proposed in addition to the S-nitrosylation of caspases (Chung et al., 2001). They include the up-regulation of cytoprotective gene products (such as heat shock protein 70) (Kim et al., 1997), heme oxygenase (Kim et al., 1995), Bcl-2 (Genaro et al., 1995), as well as increases in cGMP levels (Kim et al., 1997; Tzeng et al., 1997). All of the caspases contain a single cysteine at the catalytic site. This thiol is susceptible to redox modification and can be effectively modified by S-nitrosylation in NOgenerating conditions (Chung et al., 2001). We previously showed that NO, either synthesized by iNOS or from exogenous NO donors, suppresses caspase activation/activity in cultured hepatocytes ( $\mathrm{Li}$ et al., 1997), as well as in vivo (Kim et al., 1997; Kim et al., 2000). The antiapoptotic effect of NO was reversed by the addition of the NOS inhibitor $\mathrm{N}^{\mathrm{G}}$ monomethyl-L-arginine (NMMA), or the biological NO scavenger hemoglobin (Kim et al., 1997). Furthermore, we showed that seven recombinant members of the caspase family proteases were inhibited by redox-related Snitrosylation (Li et al., 1997). This inhibition was reversed by the reduction of the nitrosylated caspases with the strong reducing agent dithiothreitol (Kim et al., 1997), which indicates that caspase-dependent apoptosis can be modulated 
by a reversible S-nitrosylation of the active site cysteine of caspases (Kim et al., 1997; Kim et al., 2000). Stoichiometical studies revealed that the ratio of enzyme subunit to Snitrosylation was $1: 1$ in caspase- 3 and 8 following treatment with the NO-generating donor S-nitroso-Nacetylpenicillamine (SNAP) (Kim et al., 1997; Kim et al., 2000). This evidence suggests that one cysteine residue in the catalytic site is redox-sensitive against S-nitrosylation, although caspase-3 possesses more than one nitrosylated site (Stamler et al., 2001).

\section{Nitrosative stress inhibits the mitochondrial apoptotic pathway}

Mitochondria play a critical role in apoptosis in response to a variety of stimuli. These organelles release proteins into the cytosol that trigger caspase activation, and perform other functions relevant to apoptosis. Proteins that are released from mitochondria include cytochrome c, apoptosis-inducing factor (AIF), SMAC (Diablo), and endonuclease G. The mechanism by which these proteins escape from mitochondria is associated with the mitochondrial outer membrane damage by the interaction of an active caspase and Bid. Caspase- 8 cleaves Bid at $\mathrm{Asp}^{59}$ into two fragments. The C-terminal Bid fragment (p15) translocates into the mitochondrial outer membrane, and induces the release of cytochrome $\mathrm{c}$ and endonuclease $\mathrm{G}$ ( $\mathrm{Li}$ et al., 2001). The Caspase- 8 inhibitor inhibits the mitochondrial cytochrome c release and apoptosis that is induced by death receptor activation (Kim et al., 2000). We also have shown that NO inhibited the caspase-8-dependent Bid cleavage and mitochondrial cytochrome $\mathrm{c}$ release in vitro and in vivo (Kim et al., 2000). The activity of caspase- 8 can be suppressed by S-nitrosylation (Li et al., 1997). S-nitrosylated caspases inhibit the cleavage of Bid and Bcl-2, and block the release of the mitochondrial cytochrome c (Tzeng et al., 1997; Kim et al., 2000). These results suggest that the S-nitrosylation of caspases suppressed mitochondrial apoptotic events, such as the release of cytochrome c, AIF, SMAC, and endonuclease G. Therefore, the inhibition of the caspase activity by nitrosative stress can suppress a key step in the positive feedforward and feed-back amplifications of the apoptotic signaling cascade by blocking the release of mitochondriaderived apoptotic modulators.

\section{Non-heme iron enhances S-nitrosylation}

NO has weak chemical reactivity with thiols at physiological neutral $\mathrm{pH}$. Although NO alone does not interact readily with proteins or nucleic acids, some reactive nitrogen species (such as $\mathrm{NO}^{+}, \mathrm{N}_{2} \mathrm{O}_{3}, \mathrm{ONOO}^{-}$, and $\mathrm{NO}^{-}$) engage in the nitrosation of sulfur-containing biological target molecules. The strong nitrosylating agent $\mathrm{NO}^{+}$can be generated by the reaction of $\mathrm{NO}$ with $\mathrm{O}_{2}$ (Wink et al., 1993), iron-sulfur clusters (Kim et al., 2000), or other transition metals (Stamler, 1994). NO production in cells, including hepatocytes and macrophages, leads to the formation of dinitrosyl iron complexes (DNIC), as detected by electron paramagnetic resonance spectroscopy (Kim et al., 2000). DNIC carries out the S-nitrosylation of caspases through the formation of $\mathrm{NO}^{+}$-like species (Kim et al., 2000). Synthetic DNIC nitrosylates the cysteine residue in the catalytic site of caspase-3 and inhibits the enzyme activity (Kim et al., 2000). Therefore, the capacity of NO to Snitrosylate caspases may depend on the abundance of proteins that contain iron-sulfur clusters and the availability of other thiol targets, such as glutathione and free cysteine. Similarly, NO prevents apoptosis by the S-nitrosylation of caspases in iron-rich hepatocytes, but not in the iron-limited macrophage cell line RAW264.7 cells. However, the increase in non-heme iron by pretreatment with free iron is associated with greater DNIC formation and increases in the nitrosothiol formation following NO exposure. In addition, the conversion of heme to non-heme iron by NO-mediated induction of heme oxygenase- 1 increased the formation of DNIC, and protected hepatocytes from oxidative stress-induced apoptosis (Stamler, 1994; Kim et al., 2000), probably through the S-nitrosylation of caspases (Kim et al., 1999; Kim et al., 2000). The deprivation of cellular iron by desferroxamine protected the neuronal PC12 cells from NO-induced apoptosis. This suggests that the NO-mediated apoptotic cell death is dependent on intracellular non-heme iron levels (Desole et al., 1998). This evidence indicates that the cellular content of nonheme iron, such as proteins that contain iron-sulfur clusters, is a critical factor for the nitrosative stress-mediated caspase Snitrosylation and suppression of apoptosis.

\section{Nitrosative stress induces apoptosis through caspase activation}

NO generated from the NO donor, or synthesized by NOS, also induces cell death via apoptosis in a variety of different cell types. These include macrophages (Albina et al., 1993), thymocytes (Fehsel et al., 1995), pancreatic islets (Kaneto et al., 1995), certain neurons (Dawson et al., 1996; Choi, 2001), and tumor cells (Son and Kim, 1995). The factors that affect cell-specific sensitivity to nitrosative stress-mediated apoptosis can be associated with the redox state and levels of transition metal complexes within cells (Kim et al., 2000), as well as the expression of survival genes (Kim et al., 1995). Nitrosative stress-mediated apoptosis is associated with increases in the ratio of pro-apoptotic Bax to anti-apoptotic $\mathrm{Bcl}-\mathrm{X}_{\mathrm{L}}$ by the overexpression of the cell death gene p53 (Messmer and Brune, 1996), or the activation of caspase through mitochondrial cytochrome c release (Umansky et al., 2001). This results in the induction of cytotoxicity against tumor cells and normal tissues. Nitrosative stress also suppresses the DNA-binding activity of NF- $\kappa$ B by Snitrosylation (Marshall and Stamler, 2001). It can then downregulate the expression of anti-apoptotic genes, such as superoxide dismutase, TRAF1, TRAF2, c-IAP1, and c-IAP2 (Wang et al., 1998; Lee and Collins, 2001). Therefore, 
nitrosative stress can modulate the dual pathways that lead to pro- and anti-apoptosis, depending on the redox state and transition metal complexes within the cells.

\section{Conclusion}

S-nitrosylation by nitrosative stress can regulate cellular homeostasis in order to maintain the balance between the induction and prevention of apoptosis. Abnormal homeostasis is linked to many human diseases, such as cancer, which may be initiated by the suppression of apoptosis. On the other hand, hyperapoptosis may influence other disorders that are involved in vascular disease, neural disorders, and autoimmune diseases. Nitrosative stress nitrosylates the active site cysteine thiol of caspases, which are the central mediator of apoptosis in multiple biological and pathological processes. The inhibition of caspases by S-nitrosylation results in the suppression of apoptosis in several cell types. In other cell types, nitrosative stress activates mitochondria-dependent apoptotic signaling pathways that involve the activation of caspases and release of endonuclease G. Thus, nitrosative stress by NO generation, either from endogenous biological enzymes or exogenous NO donors, can serve as in vivo regulatory mechanisms of signaling pathways of apoptotic cell death.

Acknowledgment This work was supported by a Vascular System Research Center grant from KOSEF.

\section{References}

Albina, J. E., Cui, S., Mateo, R. B. and Reichner, J. S. (1993) Nitric oxide-mediated apoptosis in murine peritoneal macrophages. J. Immunol. 150, 5080-5085.

Beckman, J. S., Beckman, T. W., Chen, J., Marshall, P. A. and Freeman, B. A. (1990) Apparent hydroxyl radical production by peroxynitrite: implications for endothelial injury from nitric oxide and superoxide. Proc. Natl. Acad. Sci. USA 87, 16201624.

Beckman, J. S. and Koppenol, W. H. (1996) Nitric oxide, superoxide and peroxynitrite: the good the bad and the ugly. Am. J. Physiol. 271, 1424-1437.

Boese, M., Mordvintcev, P. I., Vanin, A. F., Busse, R. and Mulsch, A. (1995) S-nitrosation of serum albumin by dinitrosyl-iron complex. J. Biol. Chem. 270, 29244-29249.

Boldin, M. P., Goncharov, T. M., Goltsev, Y. V. and Wallach, D. (1996) Involvement of MACH, a novel MORT1/FADDinteracting protease, in Fas/APO-1- and TNF receptor-induced cell death. Cell 85, 803-815.

Brockhaus, F. and Brune, B. (1999) p53 accumulation in apoptotic macrophages is an energy demanding process that precedes cytochrome c release in response to nitric oxide. Oncogene. 18, 6403-6410.

Brown, G. C. (1999) Nitric oxide and mitochondrial respiration. Biochim. Biophys. Acta 5, 351-369.

Brune, B. and Lapetina, E. G. (1989) Activation of a cytosolic ADP-ribosyltransferase by nitric oxide-generating agents. $J$.
Biol. Chem. 264, 8455-8458.

Choi, D. W. (2001) Excitoxicity, apoptosis, and ischemic stroke. $J$. Biochem. Mol. Biol. 34, 8-14.

Chun, S. Y., Eisenhauer, K. M., Kubo, M. and Hsueh, A. J. (1995) Interleukin-1 beta suppresses apoptosis in rat ovarian follicles by increasing nitric oxide production. Endocrinology. 136, 3120-3127.

Chung, H. T., Pae, H. O., Choi, B. M., Billiar, T. R. and Kim, Y. M. (2001) Nitric oxide as a bioregulator of apoptosis. Biochem. Biophys. Res. Commun. 282, 1075-1079.

Craen, M., Declercq, W., Brande, I., Fiers, W. and Vandenabeele, P. (1999) The proteolytic procaspase activation network: an in vitro analysis. Cell Death Differ. 6, 1117-1124.

Desole, M. S., Sciola, L., Sircana, S., Godani, C., Migheli, R., Delogu, M. R., Piras, G., De Natale, G. and Miele, E. (1998) Protective effect of deferoxamine on sodium nitroprussideinduced apoptosis in PC12 cells. Neurosci Lett. 247, 1-4.

Dawson, V. L., Kizushi, V. M., Huang, P. L., Snyder, S. H. and Dawson, T. M. (1996) Resistance to neurotoxicity in cortical cultures from neuronal nitric oxide synthase-deficient mice. $J$. Neurosci. 16, 2479-2487.

Enari, M., Sakahira, H., Yokoyama, H., Okawa, K., Iwamatsu, A. and Nagata, S. (1998) A caspase-activated DNase that degrades DNA during apoptosis, and its inhibitor ICAD. Nature 391, 4350.

Fehsel, K., Kroncke, K. D., Meyer, K. L., Huber, H., Wahn, V. and Kolb-Bachofen, V. (1995) Nitric oxide induces apoptosis in mouse thymocytes. J. Immunol. 155, 2858-2865.

Fisch, C., Eu, J. P., Liu, L., Zeng, M. and Stamler, J. S. (2000) An apoptotic model for nitrosative stress. Biochemistry 39, 1040-1047.

Ignarro, L. J., Buga, G. M., Wood, R. E., Byrns, R. E. and Chaudhuri, G. (1987) Endotheilum-derived relaxing factor produced and released from artery and vein is nitric oxide. Proc. Natl. Acad. Sci. USA 84, 9265-9269.

Genaro, A. M., Hortelano, S., Alvarez, A., Martinez, C. and Bosca, L. (1995) Splenic B lymphocyte programmed cell death is prevented by nitric oxide release through mechanisms involving sustained Bcl-2 levels. J. Clin. Invest. 95, 1884-1890.

Gross, S. S. and Wolin, M. S. (1995) Nitric oxide: pathophysiological mechanisms. Аnпи. Rev. Physiol. 57, 737769.

Gruetter, D. Y., Gruetter, C. A., Barry, B. K., Baricos, W. H., Hyman, A. L., Kadowitz, P. J. and Ignarro, L. J. (1980) Activation of coronary arterial guanylate cyclase by nitric oxide, nitroprusside, and nitrosoguanidine--inhibition by calcium, lanthanum, and other cations, enhancement by thiols. Biochem. Pharmacol. 29, 2943-2950.

Ignarro, L. J., Fukoto, J. M., Griscavage, J. M., Rogers, N. E. and Burns, R. E. (1993) Oxidation of nitric oxide in aqueous solution to nitrite but not nitrite: comparison with enzymatically formed nitric oxide from L-arginine. Proc. Natl. Acad. Sci. USA 90, 8103-8107.

Kaneto, H., Fujii, J., Seo, H. G., Suzuki, K., Matsuoka, T., Nakamura, M., Tatsumi, H., Yamasaki, Y., Kamada, T. and Taniguchi, N. (1995) Apoptotic cell death triggered by nitric oxide in pancreatic beta-cells. Diabetes. 44, 733-738.

Kerwin, J. F., Lancaster, J. R. Jr. and Feldman, P. L. (1995) Nitric oxide: a new paradigm for second messenger. J. Med. Chem. 38, 4343-4362. 
Kharitonov, V. G., Sundquist, A. R. and Sharma, V. S. (1995) Kinetics of nitrosation of thiols by nitric oxide in the presence of oxygen. J. Biol. Chem. 270, 28158-28164.

Kim, Y. M., Bergonia, H. and Lancaster, J. R. Jr. (1995) Nitrogen oxide-induced autoprotection in isolated rat hepatocytes. FEBS Lett. 374, 228-232.

Kim, Y. M., Bergonia, H. A., Muller, C., Pitt, B. R., Watkins, W. D., and Lancaster, J. R. Jr. (1995) Loss and degradation of enzyme-bound heme induced by cellular nitric oxide synthesis. J. Biol. Chem. 270, 5710-5713.

Kim, Y. M., Talanian, R. V. and Billiar, T. R. (1997) Nitric oxide inhibits apoptosis by preventing increases in caspase-3-like activity via two distinct mechanisms. J. Biol. Chem. 272, 31138-31148.

Kim, Y. M., de Vera, M. E., Watkins, S. C. and Billiar, T. R. (1997) Nitric oxide protects cultured rat hepatocytes from tumor necrosis factor-alpha-induced apoptosis by inducing heat shock protein 70 expression. J. Biol. Chem. 272, 1402-1411.

Kim, Y. M., Kim, T. H., Seol, D. W., Talanian, R. V. and Billiar, T. R. (1998) Nitric oxide suppression of apoptosis occurs in association with an inhibition of $\mathrm{Bcl}-2$ cleavage and cytochrome c release. J. Biol. Chem. 273, 31437-31441.

Kim, Y. M., Bombeck, C. A. and Billiar, T. R. (1999) Nitric oxide as a bifunctional regulator of apoptosis. Circ Res. 84, 253-256.

Kim, Y. M., Chung, H. T., Kim, S. S., Han, J. A., Yoo, Y. M., Kim, K. M., Lee, G. H., Yun, H. Y., Green, A., Li, J., Simmons, R. L. and Billiar, T. R. (1999) Nitric oxide protects PC12 cells from serum deprivation-induced apoptosis by cGMP-dependent inhibition of caspase signaling. J. Neurosci. 19, 6740-6747.

Kim,Y. M., Chung, H. T., Simmons, R. L. and Billiar, T. R. (2000) Cellular non-heme iron content is a determinant of nitric oxide-mediated apoptosis, necrosis, and caspase inhibition. J. Biol. Chem. 275, 10954-10961.

Kim, Y. M., Kim, T. H., Chung, H. T., Talanian, R. V., Yin, X. M. and Billiar, T. R. (2000) Nitric oxide prevents tumor necrosis factor alpha-induced rat hepatocyte apoptosis by the interruption of mitochondrial apoptotic signaling through Snitrosylation of caspase-8. Hepatology 32, 770-778.

Kwon, N. S., Stuehr, D. J. and Nathan, C. F. (1991) Inhibition of tumor cell ribonucleotide reductase by macrophage-derived nitric oxide. J. Exp. Med. 174, 761-767.

Kwon, Y. G., Min, J. K., Kim, K. M., Lee, D. J., Billiar, T. R. and Kim, Y. M. (2001) Sphingosine 1-phosphate protects human umbilical vein endothelial cells from serum-deprived apoptosis by nitric oxide production. J. Biol. Chem. 276, 10627-10633.

Lancaster, J. R. Jr. (1994) Simulation of the diffusion and reaction of endogenously produced nitric oxide. Proc. Natl. Acad. Sci. USA 91, 8137-8141.

Lee, R. and Collins, T. (2001) Nuclear factor-kappaB and cell survival: IAPs call for support. Circ. Res. 88, 262-264.

Li, H., Zhu, H., Xu, C. J. and Yuan, J. (1998) Cleavage of BID by caspase 8 mediates the mitochondrial damage in the Fas pathway of apoptosis. Cell 94, 491-501.

Li, L. Y., Luo, X. and Wang, X. (2001) Endonuclease G is an apoptotic DNase when released from mitochondria. Nature 412, 95-99.

Liu, X., Kim, C. N., Yang, J., Jemmerson, R. and Wang, X. (1996) Induction of apoptotic program in cell-free extracts: requirement for dATP and cytochrome c. Cell 86, 147-157.

Liu, X., Zou, H., Slaughter, C. and Wang, X. (1997) DFF, a heterodimeric protein that functions downstream of caspase-3 to trigger DNA fragmentation during apoptosis. Cell 89, 175184.

Luo, X., Budihardjo, I., Zou, H., Slaughter, C. and Wang, X. (1998) Bid, a Bcl2 interacting protein, mediates cytochrome c release from mitochondria in response to activation of cell surface death receptors. Cell 94, 481-490.

Li, J., Billiar, T. R., Talanian, R. V. and Kim, Y. M. (1997) Nitric oxide reversibly inhibits seven members of the caspase family via S-nitrosylation. Biochem. Biophys. Res. Commun. 240, 419424.

Marshall, H. E., Merchant, K. and Stamler, J. S. (2001) Nitrosation and oxidation in the regulation of gene expression. FASEB J. 14, 1889-1900.

Mannick, J. B., Asano, K., Izumi, K., Kieff, E. and Stamler, J. S. (1994) Nitric oxide produced by human B lymphocytes inhibits apoptosis and Epstein-Barr virus reactivation. Cell 79, 11371146.

Mannick, J. B., Miao, X. Q. and Stamler, J. S. (1997) Nitric oxide inhibits Fas-induced apoptosis. J. Biol. Chem. 272, 2412524128.

Marshall, H. E. and Stamler, J. S. (2001) Inhibition of NF-kappa B by S-nitrosylation. Biochemistry 40, 1688-1693.

Messmer, U. K. and Brune, B. (1996) Nitric oxide-induced apoptosis: p53-dependent and p53-independent signaling pathways. Biochem. J. 319, 299-305.

Nathan, C. F. (1992) Nitric oxide as a secretory product of mammalian cells. FASEB J. 6, 3051-3064.

Nicholson, D. W., Ali, A., Thornberry, N. A., Vaillancourt, J. P., Ding. C. K., Gallant, M., Gareau, Y., Griffin, P. R., Labelle. M. and Lazebnik, Y. A. (1995) Identification and inhibition of the ICE/CED-3 protease necessary for mammalian apoptosis. Nature 376, 37-43.

Nussler, A. K., Geller, D. A., Sweetland, M. A., Di-Silvio, M. Billiar, T. R., Madariaga, J. B., Simmons, R. L. and Lancaster, J. R. Jr. (1993) Induction of nitric oxide synthesis and its reactions in cultured human and rat hepatocytes stimulated with cytokines plus LPS. Biochem. Biophys. Res. Commun. 194, 826-835.

Sakahira, H., Enari, M. and Nagata, S. (1998) Cleavage of CAD inhibitor in CAD activation and DNA degradation during apoptosis. Nature 391, 96-99.

Son, K. and Kim, Y. M. (1995) In vivo cisplatin-exposed macrophages increase immunostimulant-induced nitric oxide synthesis for tumor cell killing. Cancer Res. 55, 5524-5527.

Stamler, J. S. (1994) Redox signaling: nitrosylation and related target interactions of nitric oxide. Cell 78, 931-936.

Stamler, J. S., Lamas, S. and Fang, F. C. (2001) Nitrosylation the prototypic redox-based signaling mechanism. Cell 106, 675683.

Steller, H. (1995) Mechanisms and genes of cellular suicide. Science 267, 1445-1449.

Thornberry, N. A. and Lazebnik, Y. (1998) Caspases: enemies within. Science 281, 1312-1316.

Tzeng, E., Kim, Y. M., Pitt, B. R., Lizonova, A., Kovesdi, I. and Billiar, T. R. (1997) Adenoviral transfer of the inducible nitric oxide synthase gene blocks endothelial cell apoptosis. Surgery. 122, 255-263. 
Umansky, V., Ratter, F., Lampel, S., Bucur, M., Schirrmacher, V. and Ushmorov, A. (2001) Inhibition of nitric-oxide-mediated apoptosis in Jurkat leukemia cells despite cytochrome c release. Exp. Cell. Res. 265, 274-282.

Wang, C. Y., Mayo, M. W., Korneluk, R. G., Goeddel, D. V. and Baldwin, A. S. Jr. (1998) NF-kappaB antiapoptosis: induction of TRAF1 and TRAF2 and c-IAP1 and c-IAP2 to suppress caspase-8 activation. Science 281, 1680-1683.

Wink, D. A., Darbyshire, J. F., Nims, R. W., Saavedra, J. E. and Ford, P. C. (1993) Reactions of the bioregulatory agent nitric oxide in oxygenated aqueous media: determination of the kinetics for oxidation and nitrosation by intermediates generated in the $\mathrm{NO} / \mathrm{O}_{2}$ reaction. Chem. Res. Toxicol. 6, 23-27.

Xie, Q. W. and Nathan, C. F. (1994) The high-output nitric oxide pathway: role and regulation. J. Leuk. Biol. 56, 576-582.

Yang, J., Liu, X., Bhalla, K., Kim, C. N., Ibrado, A. M, Cai, J., Peng, T. I., Jones, D. P. and Wang, X. (1997) Prevention of apoptosis by Bcl-2: release of cytochrome $\mathrm{c}$ from mitochondria blocked. Science 21, 1129-1132.

Zhu, L., Gunn, C. and Bechman, J. S. (1991) Bactericidal activity of peroxynitrite. Arch. Biochem. Biophys. 298, 452-457. 